University at Buffalo School of Law

Digital Commons @ University at Buffalo School of Law

\title{
African Human Rights Organizations: Questions of Context and Legitimacy
}

Makau wa Mutua

University at Buffalo School of Law, mutua@buffalo.edu

Follow this and additional works at: https://digitalcommons.law.buffalo.edu/book_sections

Part of the Human Rights Law Commons

\section{Recommended Citation}

Makau Mutua, African Human Rights Organizations: Questions of Context and Legitimacy in Human Rights, the Rule of Law, and Development in Africa 191 (Gaby Oré Aguilar \& Felipe Gómez Isa, eds., University of Pennsylvania Press 2004)

Copyright @ 2004 University of Pennsylvania Press. All rights reserved. Except for brief quotations used for purposes of scholarly citation, none of this work may be reproduced in any form by any means without written permission from the publisher. For information address the University of Pennsylvania Press, 3905 Spruce Street, Philadelphia, Pennsylvania 19104-4112.

\section{IN COPYRIGHT}

This Book is brought to you for free and open access by the Faculty Scholarship at Digital Commons @ University at Buffalo School of Law. It has been accepted for inclusion in Contributions to Books by an authorized administrator of Digital Commons @ University at Buffalo School of Law. For more information, please contact lawscholar@buffalo.edu. 


\title{
An Eye Toward Effective Enforcement: \\ A Technical-Comparative Approach to the Drafting Negotiations
}

\author{
Tara J. Melish
}

The Convention on the Rights of Persons with Disabilities is a historic achievement on many levels. Hard-fought and comprehensive, it promises to change the way the rights of persons with disabilities are understood and socially claimed by a broad range of stakeholders for generations to come. This is as true for the rights of persons with physical and sensory disabilities as it is for those with psychosocial, intellectual, and other developmental or learning disabilities.

It may be noted in this latter respect that a fairly high degree of confidence existed from the beginning of the negotiations that the final drafted treaty would offer important and significant protections for persons with physical and sensory disabilities. What was far less clear was the level of protection the new treaty would offer persons with intellectual and psychosocial disabilities. Such persons have long faced a particularly abusive and deeply embedded set of social stereotypes regarding competency that have functioned in practice to institutionalize and legitimize structures that often deny their very capacity to act and make free decisions as recognized human beings. These widely held attitudes have served historically to justify, both legally and socially_-and hence to render invisible from a mainstream human rights lens-such stark abuses against such persons as their forced segregation and warehousing in institutional facilities, relegation to separate educational, housing, and employment settings, subjection to long-term 
restraints and forced interventions in the name of treatment, and enforced loss of legal capacity. Such abuses would provoke an immediate and sustained international outcry by the global human rights community if committed against persons without mental impairments, either real or perceived. ${ }^{1}$ To ensure that the acceptability of such abusive and discriminatory practices was not transposed into the new treaty, either directly or indirectly, explicit strategies of socialization, awareness raising, and legal framing would need to be a major focus of the negotiation process.

Disability Rights International-then Mental Disability Rights International-entered the negotiations with this problematic in mind, intent on ensuring that the substantive and procedural protections in the treaty were as effective and meaningful for persons with mental disabilities as they were for persons with physical and sensory disabilities. It is thus useful to highlight DRI's substantive mission and how it calculated that it could most effectively pursue this mission through the CRPD negotiation process, especially in coordination with the many other members of the disability rights movement present in the negotiations who, while differing at times in approach, were equally committed to this important goal.

This chapter is accordingly divided into three parts. The first part seeks to explain the strategic approach DRI took to the CRPD negotiation process, highlighting its methodology, the guiding principles it embraced, and the resulting strategies of engagement it pursued. The second part turns to some of the key substantive issues DRI focused on in its interventions and advocacy before the Ad Hoc Committee. The chapter concludes with a brief reflection on the Convention, the ultimate efficacy of DRI's approach, and the road ahead.

\section{DRI's Strategic Approach to the Drafting Negotiations}

Authorized to participate in the very first session of the AHC, DRI understood early on that it had a potentially important strategic role to play in the CRPD negotiation process. That role derived primarily from its institutional status and operational expertise as the leading international human rights organization dedicated to protecting the human rights and full participation in society of persons with disabilities worldwide. That is, unlike most international disability rights organizations, which have taken up the human rights framework only more recently in their global work, DRI had 
assumed an express human rights identity from its inception in 1993; it was founded precisely to make visible the human rights violations against persons with disabilities that the mainstream human rights community had long chosen to ignore. Correspondingly, with a substantive focus on ending the institutionalization of persons with disabilities and promoting their social integration into community settings where they could live with dignity and human rights on an equal basis with others, DRI's methodological focus has, since its founding, been rooted in the strategic use of international human rights treaties and their corresponding monitoring and enforcement mechanisms to achieve its advocacy objectives.

DRI thus came to the CRPD negotiating process with significant firsthand experience using existing regional and international human rights treaties, including the International Covenant on Civil and Political Rights, the International Covenant on Economic, Social and Cultural Rights, the Convention on the Rights of the Child, the Convention Against Torture, and the American and European conventions on human rights. Together with other disability rights instruments, these treaties have framed and structured the human rights methodologies and advocacy tactics DRI has employed over the last two decades. Such methodologies have ranged from detailed investigative reporting and global shaming campaigns, to grassroots training and institutional staff education, to human rights advocacy before supranational policy-making and technical forums, to regular use of UN human rights oversight mechanisms and strategic litigation before the world's regional human rights bodies. ${ }^{2}$

DRI's work program and institutional profile had two significant implications for its strategic approach to the CRPD negotiating process. First, based on the practical lessons learned from its long-term work using the existing international human rights architecture, DRI came to the process with a priority concern for maximizing the operational effectiveness of the CRPD's provisions from an institutional enforcement or implementation perspective. DRI appreciated that achieving this important objective would require close attention to the details of the treaty's technical and structural drafting. Second, and closely related, DRI was particularly alert to ensuring that the treaty contained not only strong substantive norms, but also strong procedural safeguards and independent monitoring guarantees. Such safeguards and guarantees, DRI recognized, served essential instrumental roles in the implementation process, especially as enforcement "hooks" before domestic and supranational supervisory tribunals and as necessary external 
checks on the substantive protection of rights. Such checks were particularly important for monitoring institutional policies and practices related to legal capacity, supported decision making, medical treatment, and any form of institutionalization or incarceration, all primary issues in DRI's global human rights work. Both concerns, each core to DRI's understanding of how rights are most effectively enforced in practice, affected how DRI approached its role in the negotiation process. Each is addressed more substantively below.

\section{The Treaty's Operational Effectiveness}

DRI's first strategic priority, as noted, centered on ensuring that the CRPD was technically drafted in a way that would maximize its operational enforceability before a range of domestic and international policy-making forums and legal tribunals. DRI's experience had taught it that, although a great deal can be done through purposive interpretation of human rights texts, the precise formulations through which a treaty or treaty norm is drafted can have tremendous impact on the possibilities for institutional and legal oversight. DRI thus came to the negotiation process with a priority concern not just for the recognition of critical concepts in the Convention, but also for how those concepts were technically framed and structured inter se. Accordingly, DRI saw a major part of its role in the negotiation process as seeking to improve the CRPD from a technical or operational perspective, ensuring that the treaty did not repeat mistakes or recreate normative inconsistencies that have served in practice to impede the effective enforcement of human rights under the existing international human rights architecture. This was true both for the treaty text itself and for its optional protocol.

DRI's approach was correspondingly calculated to complement that of many of the other NGOs and disabled people's organizations (DPOs) engaged in the process. Given deeply entrenched social stereotypes and the invisible status of many of the most regularized abuses committed against persons with disabilities, the majority of these civil society groups had found it necessary to focus their oral interventions and advocacy efforts on emphasizing the experiential and lived aspects of human rights abuse in the disability context. This was most frequently done through powerful personal testimonials by persons with disabilities themselves about their own 
experiences with societal and institutional discrimination, interventions that were vital to the negotiation process. ${ }^{3}$

DRI did not seek to replicate these powerful testimonials. Rather, it sought to complement and reinforce them by placing them in technical context wherever possible, especially by emphasizing their legal basis and justification within the existing international human rights law architecture and jurisprudence. It thus sought to place DPO calls for recognition of certain rights and concepts within the context of other major human rights treaties and the evolving jurisprudence of the European Court of Human Rights, the inter-American human rights bodies, the African Commission, and the many UN treaty bodies, including their general comments and observations. At the same time, it sought to expose dangers in delegate-proposed treaty language, especially with respect to the recognition of explicit exceptions to rights-based rules in the treaty text and the creation of other kinds of "let-out" clauses that would enable states to avoid taking on real legal responsibilities with respect to systemic institutional and policy reforms. In this way, DRI saw its primary role as attempting to ensure that, in substantively addressing the rights of persons with disabilities, the Convention text did not create incompatibilities with other instruments of international and regional human rights law, that it in fact strengthened existing legal protections rather than diminishing or simply repeating them, and that it was structurally well designed from a technical-operational perspective-getting the law qua law right.

DRI's particular technical-comparative approach to the drafting negotiations was, in turn, reinforced by its choice of organizational representative. For this role, it hired an international human rights attorney and legal expert in comparative human rights systems with significant experience studying and working before regional and UN human rights monitoring systems. Although this representative had worked closely with DRI on deinstitutionalization litigation and advocacy in the inter-American human rights system and had personal connections to disability, she was known to DRI as a human rights comparativist with a particular technical-legal bent. The expectation was thus that she would monitor the drafting process from the perspective of ensuring the draft convention's technical and legal compatibility with other international human rights instruments and the jurisprudence developed thereunder by the respective supervisory bodies. At the same time, DRI's representative was not new to the CRPD negotiation process. She joined DRI's legal team immediately after leaving a technical position in 
the CRPD drafting committee's substantive secretariat. She thus possessed a close working knowledge of the negotiation process from its inception, the work of the $\mathrm{AHC}$ over its prior sessions, and the evolving negotiating positions of the varied participants. Indeed, in her earlier position she had been tasked with preparing daily summaries of the key issues and points of conflict for the AHC chair, maintaining transcript notes of the proceedings, preparing background conference papers and briefings (on such issues as comparative national approaches to reasonable accommodation), and attending intersessional Bureau meetings of the Committee.

Consistent with this technical focus, DRI adopted a particular methodology of engagement in the negotiation process. First, following its representative's practice as UN social affairs officer, DRI maintained a close-to-verbatim transcript of all delegate interventions in the AHC. Shared on a daily basis with all requesting state delegations, national human rights institutions, UN officials, and civil society participants, this unofficial transcript was used to keep track of how many states supported or opposed each issue as well as the specific arguments or justifications used to defend those positions. ${ }^{4}$ By scrupulously recording and monitoring the precise positions of all parties, DRI sought to make its interventions as targeted and value additive as possible. Interventions were structured in particular to do five principal things.

First, DRI aimed never to make abstract or merely conceptual points. Rather, it sought to respond directly to technical issues raised in debate that suggested misinterpretations or misapplications of international human rights law. It would, accordingly, begin each intervention by recognizing its satisfaction or significant concern with the positions taken by specific sets of states on a given issue or draft article. Briefly expressing its support for the substantive positions already highlighted by other DPOs, NGOs, and Committee members, it would then focus its observations on two to four technical issues that had not yet been raised in the discussion that could nonetheless shed light on the text under debate.

Second, in raising these technical issues, DRI sought explicitly to situate its responses to delegate proposals within the context of recognized international law principles, both substantive and interpretive. It accordingly frequently sought to allay delegate concerns as to specific language choices or textual terminology by explaining their foundational basis in or consistency with authoritative interpretations of $\mathrm{UN}$ and regional human rights bodies in their evolving jurisprudence. DRI's interventions thus cited broadly to the provisions and interpretations of other treaty texts as a way to ground 
and substantiate the proposals of civil society groups and friendly states. It did so even while insisting on the need not to fall into the trap of merely reconstituting existing norms in the CRPD; indeed, the treaty's very raison d'être was to relate existing norms to the specific experience of persons with disabilities and the distinct ways their rights are impacted by widespread social, attitudinal, institutional, and architectural barriers.

In this respect, DRI's interventions sought to mediate two of the dominant thematic tensions running throughout the drafting process, constantly reminding states of the early decisions that had been made thereon. The first related to the treaty "model" the CRPD was to follow. A major debate in the first two AHC sessions involved whether the new treaty was to follow a narrow "nondiscrimination" model (like the Convention Eliminating All Forms of Discrimination against Women and the Convention on the Elimination of All Forms of Racial Discrimination), a "comprehensive" model (like the CRC), or a "hybrid" model that combined elements of the two. The general consensus arrived at by the AHC in authorizing the Working Group to proceed with a draft text was that the CRPD should follow a hybrid model. This approach was vital, it was agreed, given the recognized failure of existing treaty language to ensure in practice the rights of persons with disabilities worldwide. Accordingly, explicit substantive specification of the precise ways in which the human rights of persons with disabilities were regularly violated was indispensable to the treaty's instrumentality and purpose. In floor debate, states nevertheless repeatedly tried to return to a mere nondiscrimination model, simply repeating rights already recognized in existing treaties and hence losing the distinctive quality of the disability-specific text.

This tendency was reinforced by a closely related thematic tension, one that continues to raise challenges in the post-adoption ratification and implementation stages. That tension arises from the interpretive friction between two assertions regarding the CRPD, both correct and each raised consistently throughout the drafting process. First, the CRPD creates no new rights in international law. Second, in affirming the substantive equality of existing rights in their application to persons with disabilities, the CRPD recognizes the distinct ways that those rights are lived and experienced by persons with disabilities on a daily basis-experiences that often differ quite substantially from those of persons without disabilities. Indeed, it is precisely because of this differential treatment, and particularly the justificatory assumptions underlying them, that the rights of persons with disabilities have for so long 
remained invisible from the mainstream human rights lens. DRI thus repeatedly found itself affirming the basis of textual provisions in existing international human rights law, while defending textual wording that departed from existing treaty language in its recognition of the distinct ways those rights are experienced by persons with disabilities. ${ }^{5}$

Third, in relating its technical points to the specific proposals raised in floor debate, DRI made an express point of specifying by name each of the individual states that had offered positions on the issue, identifying those positions as either consistent or inconsistent with international law principles. It did so not only for situational and legitimation purposes, but also for reasons of peer-based persuasion and socialization. The interventional tactic was thus directed toward recognizing and affirming as international norm leaders those states supporting pro-persons with disabilities positions, encouraging them to continue taking such positions. Correspondingly, by expressly naming states taking positions inconsistent with international law principles or harmful to the equal rights of persons with disabilities, DRI sought to identify them before their peers as human rights outliers, situated outside the mainstream human rights consensus. It was hoped that a dynamic would be promoted through which state delegations would seek to take public positions that grouped them with international norm leaders.

At the same time, on a more direct tactical level, because DRI often raised narrow technical issues that might not independently generate direct floor debate, it sought to identify its positions with specific proposals already raised by identified state delegations. The purpose was to make it easy and natural for those delegations to make the points their own, directly incorporating them into their own proposals, advocacy, and peer-based consultations with other states. This was particularly important given the relative lack of time DRI's representative had for broad-based consultations with state delegations, given the corresponding need to maintain a detailed record of delegate interventions and to prepare DRI's own article-by-article oral interventions.

Fourth, DRI sought to avoid repeating points raised effectively by others or for which there was already a clear consensus in the Ad Hoc Committee. Rather, it sought to "add" to what other civil society and state actors had said by focusing on points not yet raised in floor debate and/or by providing a perspective or explanatory approach that differed from, but complemented, that which had already been taken by state delegations and other DPO and 
NGO leaders, especially the International Disability Caucus. As explained below, DRI was not able to join the IDC given certain tactical differences in approach regarding the most effective way to protect key rights related to legal capacity and institutionalization. It nonetheless sought to support IDC positions in all other areas of substantive advocacy.

Finally, and relatedly, DRI used the technical focus of its interventions to try to find consensus positions or "ways through" substantively divisive or otherwise difficult issues. ${ }^{6}$ The offer of a "neutral" technical perspective was frequently very helpful in this regard, especially when participants appeared to be talking past each other on the underlying substantive issue or as a way to explain principled text to skeptical delegations in ways they might be more inclined to comprehend. This was particularly important on such issues as inclusive education and the lack of need, from a practical or legal perspective, to recognize specific exceptions or qualifiers to rights in the text of the treaty. In this latter regard, recognizing the basis of a provision in another treaty or underscoring the practical methodologies used by human rights bodies to interpret distinct norms, especially those that created significant positive obligations for states, often helped to quiet concerns that treaty language was creating impossible standards for states to meet and hence needed to be explicitly qualified in the text.

DRI thus sought to articulate major points in ways that could be "heard" both by skeptics on state delegations and by the more technically minded participants in the negotiations. The utility of this perspective was often apparent in the relative quieting of the committee room when DRI made its oral interventions and in the number of delegations asking for written copies of the same. This neutral technical focus was also used to mediate certain disagreements within the disability community itself. Indeed, by underscoring the international law basis of discrete components of competing interest-based positions, DRI sought to identify textual pathways that could meet the core interests of all affected constituencies. ${ }^{7}$

Strong Procedural Safeguards and Independent Monitoring Guarantees

DRI's second priority concern in the negotiating process lay in ensuring that the Convention's substantive norms were accompanied by strong procedural safeguards and independent monitoring guarantees. DRI was con- 
vinced that the Convention would provide little protection for persons with disabilities if it did not provide expressly for independent monitoring of the treaty's substantive protections by civil society groups and persons with disabilities themselves. At the same time, it was alert to the fact that international human rights supervisory bodies often mediate their subsidiary role as guarantors of rights vis-à-vis domestic authorities by relying preferentially on procedural safeguards and other procedural hooks as a way to leverage the substantive protection of rights. This is particularly true where such bodies must balance competing rights and/or legal duties held by the state and where substantive agreement as to the scope of the underlying norm has not yet been sufficiently concretized in the circumstances at issue, necessitating a certain margin of appreciation for local authorities. Accordingly, ensuring the existence of strong procedural safeguards and enforceable process commitments throughout the text of the treaty was a particular priority for DRI in ensuring the treaty's operability in post-adoption implementation processes.

This principled priority concern nevertheless had an important implication for DRI in the negotiating process: it prevented the organization from being able to join the IDC. The IDC had been created to coordinate the positions of the vast number of civil society groups participating in the negotiation process, allowing them to advance a common platform and speak with a single voice, thereby amplifying their presence, persuasiveness, and authority as equal negotiating partners. A "consensus" program, the IDC platform nonetheless incorporated certain "nonnegotiable" positions that not all organizations could accept. In particular, at the urging of key groups in the psychosocial disability community, such as the World Network of Users and Survivors of Psychiatry (WNUSP), ${ }^{8}$ the IDC had adopted a nonnegotiable position on the issues of institutionalization and legal capacity. That position would accept nothing less than a full and express prohibition in the treaty on both civil commitment and forced treatment. To underscore the absoluteness of the dual prohibitions, the IDC had taken the negotiating position that it would accept no legal safeguards in the text of the treaty with respect to either. DRI, it is important to emphasize, agreed unreservedly and categorically with the IDC on the underlying substantive issues: as a matter of principle, DRI opposes forced treatment and believes that all institutions can be closed. ${ }^{9}$ Nonetheless, as a tactical matter, it recognized that there are many ways to achieve these ends, and an absolute prohibition might not be the most effective way of doing so. 
Indeed, from a pragmatic perspective, the achievement of a direct prohibition in the treaty appeared largely unrealistic with respect to what states could politically be expected to adopt in a legal instrument at the present time. Far more important, by forfeiting some of the most effective treatybased tools for ensuring the protection of the critical underlying substantive rights, the position appeared shortsighted and even counterproductive from an operational perspective. Given that every country we know of today permits institutionalization and forced treatment, DRI believed that indirect ways of pressuring and incentivizing governments to change practices may be the best strategy for achieving the disability community's shared objectives.

To be able to freely advocate this tactical position in the negotiation process and to offer specific language proposals with respect to procedural protections, hard process commitments, and independent monitoring guarantees designed to promote participation, oversight, and transparency, DRI was accordingly compelled to remain formally outside the IDC. ${ }^{10}$ This is true even as it supported IDC positions on virtually every issue in the negotiation process-including the IDC's evolving position on procedural safeguards by the end of the negotiations.

\section{Guiding Principles for DRI Interventions}

All the above led DRI to approach the CRPD drafting process with a certain set of guiding principles in mind. These principles reflect the primary thrust of DRI's interventions and advocacy in the AHC, including with respect to the key issues in the negotiations highlighted below.

DRI's first priority, as already underscored, was to ensure that no language included in the treaty was weaker than or inconsistent with that found in existing international human rights law instruments. It thus structured its interventions around existing norms of international law, explaining in as accessible language as possible why distinct state drafting proposals were either consistent or inconsistent with recognized international law principles and the evolving jurisprudence thereon. This was as true with respect to substantive norms-such as attempts to dilute international human rights standards on the rights to health, work, and education, and on state duties to ensure against discrimination in private settings-as it was with respect to the inclusion of paternalistic language and inappropriate qualifiers on rights such as "endeavor to" and "to the extent possible."11 
Second, DRI's interventions repeatedly insisted that the Convention must be one of broad principles, not detailed exceptions. DRI thus constantly challenged state proposals seeking to insert express exceptions to rights norms or their correlate duties in the draft treaty, especially where the rights of persons with mental disabilities were at issue and with respect to resource commitments. A prominent cohort of states even tried to insert a footnote into the Convention-a dangerous practice followed in no other human rights treaty-that would exempt them from any obligations relating to the guarantee of legal capacity for persons with disabilities, citing the lack of separate words for "legal capacity" and the exercise thereof in their national languages. "In Arabic, Chinese and Russian," the footnote would have read, "the term 'legal capacity' refers to the capacity for rights, rather than the capacity to act." Allowing exceptions such as these and others into the text of the treaty, DRI insisted, would significantly undermine its very object and purpose as an instrument to ensure the equal rights of persons with disabilities. Indeed, as Liechtenstein's delegate had aptly observed, doing so would be like enumerating all the ways child discipline is permitted under the CRC, or that persons can in fact be treated differently under the ICCPR. This is decidedly not the purpose of a human rights treaty, a key point to which DRI consistently returned in its interventions.

At the same time, DRI believed it equally imperative that the treaty not overly detail or predetermine the content of rights. The treaty would be most effective, DRI believed, if its guarantees were recognized in broad, open-textured ways, contoured by the overarching principles of dignity, inclusion, social agency, and participation. This was true over both space and time. Indeed, such texture would allow interpretation and implementation strategies to vary as necessary over distinct geographies, allowing the treaty to be maximally responsive to the varied contexts, realities, imaginations, and changing priorities of affected communities around the globe. On the other hand, it would ensure the interpretive elasticity necessary for treaty norms to evolve progressively with time and comparative experience-a quality of particular import as the world disability community gathers strength, social consensus shifts, and new opportunities and barriers present themselves. Indeed, because all rights are bounded by social expectations and evolving context, such normative elasticity is crucial for the long-term relevance and responsiveness of all rights-based strategies, platforms, and creative discourses.

A third principle guiding DRI's interventions was the insistence that the CRPD's substantive norms must be framed and recognized as rights, not 
merely as state duties or general undertakings. As experience with other treaties has shown, this technical framing is important for ensuring that human rights treaty provisions can in fact be effectively claimed as rights by individuals before international tribunals and other supervisory mechanisms. ${ }^{12}$ DRI was thus highly vigilant to attempts by delegations, whether intentional or unintentional, to remove references to rights in the course of redrafting provisions. ${ }^{13}$ It specifically challenged such attempts, for example, with respect to the draft norms on accessibility, access to justice, inclusive education, reasonable accommodation, and habilitation and rehabilitation.

Similarly, DRI paid close attention to the evolving structure of the draft treaty and, specifically, to where norms were placed therein. For example, the treaty was long divided substantively into separate parts. Part I encompassed the treaty's purpose, general principles, and general obligations, while Part II included the treaty's substantive rights. When the Australian delegation thoughtfully called for the movement of the provision on accessibility to a higher position in the Convention to reflect its central importance thereto, the provision was nonetheless moved from Part II to Part I. DRI intervened to insist that Australia's well-intentioned objective was not served, and in fact was undermined, by the provision's movement into Part I where it would no longer be interpreted as an autonomous right, but rather as a general obligation. This was important from an operational perspective, DRI believed, as the norm would now need to be affirmatively paired with a substantive norm from Part II for its direct enforcement, at least by an international tribunal. (The same was true, DRI argued, with respect to the recognition of nondiscrimination exclusively in Part I, rather than as a norm that should appear in both parts, as in most other human rights treaties. It conversely applied to the AHC's failure to include a duty to provide effective remedies in Part I to accompany the late-added guarantee of effective access to justice in Part II.)

In direct response to these technical arguments, the Committee agreed to remove all textual references to structural "parts" from the treaty. It thereby sought to obviate any interpretive inference that the referenced norms were intended to be understood exclusively as duties. As with many issues, this was not the ideal technical solution from DRI's perspective. It was nonetheless an important technical modification that would be highly consequential for the treaty's post-adoption interpretation under general principles of international law. 
Fourth, DRI was consistently guided by the precept that the treaty's individual norms should directly and textually reflect the principles of social inclusion, community integration, participation, and individual development, as was generally done in the Working Group draft. Inclusion of such language was operationally important at the implementation stage, DRI believed, for ensuring a broad, relevant, and evolving interpretation of the treaty's norms in distinct national and disability contexts. It was particularly important for avoiding interpretations based on "formal equality" reasoning alone and, specifically, for preventing the conversion of treaty norms into "benefits traps," that is, interpreted to allow services to be provided in ways that lead to further segregation of persons with disabilities. Such separate systems are often expressly justified in national systems under "equality" rationales-frequently with explicit exemptions for minimum wage requirements and other labor protections for persons with disabilities in employment contexts and through the offer of mere busywork, rather than work that promotes individual dignity, development, and social inclusion.

At the same time, DRI was highly sensitive to the loss of key language from individual provisions when norms were split apart or other drafting modifications were made, often in an attempt to simplify language or to accord the CRPD provisions with existing human rights treaty norms, especially those of the International Covenant on Civil and Political Rights. The result of this "simplification," or streamlining process, was often to lose the very specificity and relevance of the CRPD to the disability context. The draft norms on freedom from torture and personal integrity, for example, were not only needlessly divided into separate articles, but were streamlined to repeat almost verbatim the text of the ICCPR. ${ }^{14}$ There were likewise strong, but ultimately unsuccessful, efforts to remove references to free and informed consent from the norm on the right to health. As indicated previously, the effect of removing the disability specificity of such norms largely obviates the need for a separate disability convention. Accordingly, while DRI acknowledged the benefits of streamlined text for the clarity and elegance of the treaty, it repeatedly underscored the necessity of not allowing important conceptual elements of rights to get lost in the streamlining process.

Finally, as already noted, DRI's interventions were closely attuned to the inclusion of strong procedural safeguards for ensuring substantive rights norms and hard process commitments for achieving rights-based outcomes. It was thus a strong advocate of independent international monitoring, as 
well as robust and mutually reinforcing procedural safeguards for any form of intervention in the freely decided life choices of persons with disabilities.

\section{Key Issues in the Negotiations}

The methodologies and guiding principles described above governed DRI's interventions with respect to all substantive norms of the Convention. Below, a few of the key substantive issues focused on as part of DRI's participation in the AHC are likewise described. Although many of the important arguments and issues DRI advanced are not captured here, a taste is offered.

\section{Legal Capacity and Procedural Guarantees for Supported Decision Making}

For DRI, as a human rights NGO focused primarily on ending human rights violations committed against persons with disabilities as a result of abusive civil commitment procedures and guardianship practices, forced institutionalizations and treatment, social and residential segregation, and lack of available support for living in the community on an equal basis with others, the level of protection the CRPD would offer against these practices was the organization's top priority in the negotiation process. The question of legal capacity and the ability of persons with disabilities to make free and informed decisions about where and with whom they live, what medical interventions they consent to, and other basic personal decisions about their bodily integrity and private lives were particularly central to DRI.

To DRI's satisfaction, the final text of the CRPD provides multiple layers of protection with respect to many of these issues, including in Articles 14, $15,17,18,19,22$, and 25 . DRI made substantive interventions with respect to all of these provisions, consistently affirming the need for strong safeguards on and guarantees for ensuring decision-making autonomy and the availability of real options for inclusion and participation in the community. Article 12 was nonetheless vital to DRI's organizational principles and priorities. It enshrines the right of persons with disabilities to recognition of their legal personality and to the enjoyment of legal capacity on an equal basis with others in all aspects of life. 
It is important to highlight in this regard that substantial agreement existed in the AHC on the need for recognition in the treaty of this broadly phrased right. Far less consensus existed on questions involving the exercise of that capacity. Indeed, the issue was volatile, threatening at times to undermine the entire negotiation process. The volatility revolved specifically around the following question: To what extent and under what conditions, if any, can the exercise of legal capacity lawfully be limited or even fully denied?

Large numbers of participants in the process took opposing positions on this important question. At one extreme, a sizable number of states rejected the idea that persons with disabilities, especially those with intellectual and psychosocial disabilities, could in fact make decisions on their own or live in the community independently. Accordingly, they rejected the idea that civil commitments and substituted decision making could be prohibited outright, arguing that involuntary institutionalization and forced treatments are at times both necessary and beneficial, especially to protect the safety of persons with disabilities themselves or others in the community. They correspondingly sought to enshrine specific exemptions into the treaty to recognize the right of states to civilly commit, provide nonconsensual treatment to, or assert guardianships over persons with mental or other impairments in such situations. At the other extreme, the IDC, pressed by vocal and powerful groups like the WNUSP, had adopted the converse stance as one of its nonnegotiable positions: it refused to accept the legitimacy of any treaty that authorized or permitted the civil commitment, institutionalization, or involuntary treatment of persons with disabilities under any conditions, even under limited circumstances and with significant due process protections.

For DRI, getting this issue right was crucial for the Convention. As noted, given present realities in the world, including the number of institutions operating in all regions of the globe, it did not believe that inclusion of an outright prohibition on institutionalization or forced treatment in the Convention was politically feasible. Nor did it believe the final treaty would allow for no permissible limitation of any kind on the autonomous exercise of legal capacity. More importantly, given reservation, nonratification, and other legal "exit" options open to states, it was not convinced that the textual inclusion of such absolute prohibitions in the treaty would necessarily constitute the most effective way of achieving the two priority objectives it unequivocally shared with the IDC leadership-ending the institutionalization of all persons with disabilities as quickly as possible and maximizing individual autonomy in all personal decision making about life choices. 
Accordingly, DRI took a position in the negotiation process that aimed toward three complementary objectives. Each directed at promoting a proactive dynamic of progress and protection at the implementation stage, they included: (1) ensuring the strongest possible state commitments and legal duties with respect to the affirmative right of all persons with disabilities to live independently in the community with the support services they need (that is, not in institutions); (2) supporting overlapping protections for choice and autonomous decision making in as many treaty provisions as possible (that is, not limited to a single prohibitory provision); and (3) ensuring that any assistance lawfully provided to persons with disabilities in exercising their legal capacity was governed by the principle of supported (not substituted) decision making and, likewise, was surrounded by strong and multiple procedural safeguards. Taken together, DRI believed these positions would not only promote the strongest state buy-in and participation for ending institutional warehousing and nonconsensual or abusive treatments, but would also create the greatest number of implementation hooks and entry points for independent monitoring, participatory oversight, and effective enforcement.

DRI's interventions supported this three-prong approach. With respect to the third prong, DRI played a particularly active role in ensuring that the text of Article 12 expressly included multiple legal safeguards, substantive restraints, and review requirements for any possible limitation on the exercise of legal capacity. Citing the extensive safeguards already developed in international human rights jurisprudence and in relevant disability instruments, DRI was particularly insistent on textual inclusion of three requirements, each viewed as necessary for preventing abuse and ensuring respect for the rights, will, and preferences of the person: (1) strict proportionality and tailoring to actual individual need in the circumstances; (2) application of any limitation or restraint on autonomous decision making for the shortest time possible; and (3) regularized review by independent judicial authorities. In achieving the inclusion of these essential safeguards, it sought to work with and support friendly state delegations strongly committed to a similar approach, such as New Zealand and Israel. The final text of Article 12(4) correspondingly reads:

States Parties shall ensure that all measures that relate to the exercise of legal capacity provide for appropriate and effective safeguards to prevent abuse in accordance with international human rights law. 
Such safeguards shall ensure that measures relating to the exercise of legal capacity respect the rights, will, and preferences of the person, are free of conflict of interest and undue influence, are proportional and tailored to the person's circumstances, apply for the shortest time possible and are subject to regular review by a competent, independent and impartial authority or judicial body. The safeguards shall be proportional to the degree to which such measures affect the person's rights and interests.

By providing key leverage points for supervisory enforcement, the operational effectiveness of this "safeguards approach" for preventing unjustified institutionalizations and arbitrary deprivations of legal capacity has already proven itself in practice. Indeed, the European Court of Human Rights has found express violations of the European Convention on Human Rights where persons have been deprived of their legal capacity without the provision of appropriate, proportional, and strictly tailored safeguards, including regular review. ${ }^{15}$ As an interpretive tool, Article 12(4) will undoubtedly continue to be a vital enforcement hook for issues of institutionalization, civil commitment, and guardianships before courts and human rights supervisory bodies around the world. ${ }^{16}$

A second key issue in Article 12-one that is central to the entire treaty in shifting the disability paradigm toward a social model-is its codification of the principle of supported decision making in place of substitute decision making. It recognizes in this regard that there may be times in a person's life in which he or she needs assistance in making certain personal life decisions. The practice in such circumstances has historically been to appoint a guardian or substitute decision maker, often a family member or the director of an institutional facility, who then becomes the exclusive decision maker for the person. Such substitute decision making is effected even where persons with disabilities can express their own will and preferences with respect to a given decision or decisions (with or without support) and even where guardians possess substantial conflicts of interest with those persons. Article 12 seeks to end this abusive practice, one that lies at the core of so many other regularized abuses committed against persons with disabilities. It does so by requiring that states ensure that persons with disabilities have reliable access to the support they may require in exercising their legal capacity and, correspondingly, by expressly constraining the level of support that can be provided to that which is strictly necessary for the individual at the 
moment the decision is taken. Where support exceeds this level, Article 12 is implicated.

Both of these aspects of Article 12 will prove vital for protecting persons with disabilities from the regularized abuse they have experienced both in institutions and at home. This is especially true with regard to their ability to decide where and with whom they will reside and what medical interventions they will consent to, to own and inherit property, to control their own financial affairs, to have equal access to financial credit, and to decide the number and spacing of their children as well as other personal life decisions at the core of being human.

\section{Living Independently in the Community}

Closely related to Article 12, a second core priority for DRI in the negotiation process was Article 19, "Living Independently and Being Included in the Community." Indeed, in its day-to-day work, DRI has mounted concerted international human rights campaigns against building or rebuilding institutions for persons with disabilities worldwide, insisting that government and donor funds be used instead to invest in safe and dignified communitybased services and appropriate supports so that persons with disabilities can live independently in the community on an equal basis with others. Correspondingly, its top institutional priority is its Worldwide Campaign to End the Institutionalization of Children, a campaign directed against both governments and donor agencies that continue to fund the building or rebuilding of institutions for persons with disabilities. ${ }^{17}$

A provision in the treaty expressly guaranteeing the right of persons with disabilities to live independently in and be included in the communityand creating correlate duties for ensuring access to the resources and support services necessary for the enjoyment of that right-was thus central to DRI's political priorities. As highlighted above, such a provision would serve as a positive and proactive way to achieve the ultimate goal of ending the institutionalization of persons with disabilities. The key challenges DRI faced to such a provision came in the form of two widely repeated arguments by states. The first was that the draft provision created a new right not recognized in other human rights treaties; it thus exceeded the Committee mandate and could not be included in the treaty as a right. Second, and related, a 
large number of states argued that they lacked the resources as a practical matter to ensure that all persons with disabilities could live independently in the community and that, accordingly, the referenced norm could not be recognized in the Convention as a legal right, but only as a programmatic goal.

DRI used its oral interventions to respond from a technical-comparative perspective to each of these arguments. With respect to the former, DRI underscored that the "right to live in the community" was simply a straightforward articulation of the widely recognized international norms to nondiscrimination and freedom to choose one's residence, rights expressly recognized in the ICCPR and all three regional human rights treaties. Correspondingly, just as a state may not restrict a person's options to reside in any particular section of a country, city, or town on account of racial, religious, or political grounds, neither may it limit the options of a person to live in the community on account of his or her disability-by, for example, restricting a person's residential options to an institution or other particular living arrangement, either directly or indirectly. Such limitations constitute unambiguous discrimination under international law. Just as in other settings where societal discrimination has functioned to create segregated social environments, states have clear affirmative legal obligations to take all appropriate and necessary measures to ensure that persons with disabilities can enjoy freedom of living arrangement on an equal basis with others.

With respect to the second argument, DRI underscored a similar legal point to that which it had made throughout the negotiations: ensuring the effective enjoyment of human rights on an equal basis by all is an expensive and resource-intensive undertaking with regard to all rights. It is precisely for this reason that states undertake the conduct-based obligation to take all "appropriate" measures to ensure the enjoyment of rights, with the definition of what is "appropriate" necessarily responsive to local realities. All major human rights tribunals and supervisory bodies take this distinction into account in their individual-rights jurisprudence. Accordingly, the fact that enjoyment of a right cannot be achieved in full immediately for all rightsholders is not a legitimate or credible justification for not recognizing it as a "right." Indeed, if it were, we would recognize no human rights in international treaties, including the right to equal treatment on grounds of race, gender, or religion-the full enjoyment of which has not yet been achieved in any national community. 
The right to equal treatment, then, is a work in progress with respect to all grounds of discrimination. The instrumental purpose of international human rights law, DRI insisted, is to create legal duties for states to take all appropriate and necessary measures to ensure, without delay and on a targeted basis, the enjoyment of rights by all rights-holders on an equal basis. Such conduct-based measures include reviewing and revising national legislation and policies, training officials in their human rights obligations, creating benchmarks and plans of action to achieve specified human rights targets, closely monitoring progress and setbacks, constantly measuring and evaluating performance, and correspondingly changing policy and practice as necessary. In this respect, the distinction between "legal rights" and "programmatic goals" is a false one, long used as a smokescreen for avoiding positive obligations for rights in the social field that are fully and unquestioningly undertaken with respect to rights in other fields.

\section{Inclusive Education and Work Environments}

As a human rights NGO committed to ending the segregation of persons with disabilities in all institutional settings and environments, DRI was likewise highly motivated with respect to ensuring the treaty's guarantees on inclusive education and inclusive work environments, enshrined in $\mathrm{Ar}$ ticles 24 and 27, respectively. With respect to the former, DRI played an active advocacy role in a number of the very technical aspects of Article 24. Its most important contribution, however, lay in helping to ensure the deletion of a very strongly supported textual exception to the principle that education should always be inclusive. ${ }^{18}$ That exception would have expressly provided that "separate education shall be provided" in those circumstances where the general education system cannot adequately meet the educational needs of persons with disabilities. Together with other NGOs and DPOs, DRI argued that this exception would effectively swallow the rule, providing an explicit "let-out" for states to justify maintaining separate educational systems for persons with a wide range of intellectual, physical, and sensory impairments. The Convention, DRI insisted, should not be one of exceptionsno international human rights treaty is-but rather one of strong principles and commitments to work toward systematically on a targeted and tireless basis. 
Revealingly, the states supporting this provision argued explicitly that the individualized needs of persons with intellectual disabilities cannot be met in the general education system, and thus the Convention needed to recognize the appropriateness or acceptability of separate education for persons with mental disabilities. In the end, the provision was bitterly fought over, with China serving as the holdout until the very last, eighth session. With consensus unable to be reached in floor debate, the final text had to be negotiated privately in state-to-state consultations and informal small group settings. Within this struggle, Australia, the principle state supporter of deleting the offending phrase on separate education, expressly requested assistance from DRI on how most effectively to frame the legal issues for China's delegation.

DRI likewise attempted to offer a technical perspective drawn from comparative human rights law to help mediate a significant conflict on the point of separate education within the disability community itself. That is, groups supporting the rights of persons with intellectual disabilities tended to support vigorously the inclusion of an unqualified "right to inclusive education" in the treaty, accompanied by a correlate "prohibition" on separate education systems. ${ }^{19}$ By contrast, the deafblind community preferred a "twin-track" approach that would expressly recognize the right to separate education systems or state-financed "special" schools for the deaf and blind. In deference to the deafblind community, the IDC had adopted the latter view as one of its principle platforms, emphasizing the right to "choice" between separate or inclusive education by persons with disabilities themselves.

DRI sought to mediate this conflict by recognizing two distinct but complementary points from international human rights doctrine. First, in insisting on the removal of the general reference to "choice of inclusive education" for persons with disabilities in favor of a textually unqualified right to inclusive education for all, ${ }^{20}$ DRI underscored that the "right to educational choice" in current international law is in fact highly limited. Parents and guardians do not enjoy a general right to choose a specific type of public educational system for their children. Rather, they enjoy only the liberty to remove their children from the general public education system, "choosing" to place them instead in a private system or home-schooling environment that nonetheless conforms to minimum educational standards laid down by the state. A broad reference to "choice" within the general education system therefore lacks support in international human rights law at present and should be replaced, DRI concluded, by a focus on ensuring the right to an 
inclusive education system at all levels and access to such education in the communities in which persons with disabilities live.

At the same time, however, DRI underscored that international law does recognize that certain defined subgroups with their own cultural identity and specific needs may be entitled to state funding to establish their own educational institutions. Grounded in the internationally recognized right to culture, major international instruments enshrining the rights of indigenous persons, for example, recognize their right to establish and administer their own educational institutions and facilities, accompanied by a correlate state duty to provide appropriate financial resources, assistance, and training in administering them. ${ }^{21}$ Accordingly, just as textual recognition of a broad "right to educational choice" would lack an established international law basis, so too would a "prohibition" on separate education systems.

DRI made these technical points in the sixth session, recalling them in the seventh and eighth, to underscore the international law basis for supporting both positions within the disability community: the imperative of recognizing a broad and unqualified "right to inclusive education" for all, while not in the process undermining the right of certain culturally self-identifying groups, such as members of the deaf, blind, and deafblind community, to establish their own educational institutions if it is their choice. The final text of Article 24 reflects this doctrinally grounded "compromise" position. It also reflects the caution that should, in DRI's view, generally be exercised in any human rights treaty drafting process with respect to the codification of absolute prohibitory language. In most cases, positively worded guarantees to affirmative conduct or outcome-based results not only will open a greater diversity of creative and multileveled enforcement options, but may also avoid significant unintended consequences for differently situated social groups that are negatively affected, including those not well represented in the negotiation process.

\section{Monitoring and Enforcement Mechanisms}

Finally, with its focus on post-adoption implementation processes and based on its on-the-ground experience working with states to ensure deinstitutionalization and community integration, DRI actively intervened on ques- 
tions of monitoring and enforcement at both the national and international levels throughout the negotiation process. In this respect, it strongly agreed with Senegal's observation that the CRPD provisions on monitoring and enforcement would serve as the "soul" of the Convention, determining how it would be implemented on the ground.

With respect to national-level mechanisms, DRI was particularly insistent on ensuring that the Convention include strong independent monitoring provisions, especially for service provision in both closed institutions and community settings. Thus, in addition to systems for general monitoring, it emphasized that the Convention should provide for specialized, independent monitoring to protect the rights of people who are especially vulnerable, including but not limited to those receiving services in institutions or other closed environments. DRI could not close its eyes in this regard to the fact that millions of children and adults around the world remain segregated from society in closed institutions, within which they often lack the means to publicize abuses or claim their own rights. At the same time, as countries move away from institutions toward community-based services and supports for persons with disabilities, more and more abuses are found in the community. Often, what are called "community services" are actually small, isolated institutions located in physical proximity to what could be called the community. Thus, any oversight and monitoring system must also monitor rights protection in community-based services.

While highlighting numerous comparative models of effective rights oversight and monitoring bodies from around the world, DRI focused in particular on the standards adopted by the Council of Europe in 2004 with respect to mental health institutions. ${ }^{22}$ These standards specify that, to avoid a conflict of interest and to ensure that abuses by an institution can be challenged, oversight and monitoring must be conducted by a body that is "organizationally independent from the authorities or bodies monitored" and should include not only mental health professionals and laypersons, but also persons with disabilities and those close to them. ${ }^{23}$ Importantly, they likewise provide that regular visits and inspections should be able to be undertaken without prior notice and that systematic and reliable statistical information and information on implementation should be made available to the public. ${ }^{24}$ At the same time, following the UN Standard Rules on the Equalization of Opportunities of Persons with Disabilities, which explicitly recognize the rights of persons with disabilities to be involved in monitoring and 
implementation of human rights that affect them, DRI strongly supported the early proposals of Sierra Leone and Yemen to expressly incorporate the guarantee of direct participation by persons with disabilities and civil society organizations in the treaty monitoring process. This proposal was explicitly incorporated into Article 33(3), decidedly one of the most important provisions in the treaty.

DRI was also successful in ensuring that a provision on effective monitoring by independent authorities of all facilities and programs designed to serve persons with disabilities was directly included in Article 16 of the Convention, which guarantees "freedom from exploitation, violence and abuse."

With regard to an international monitoring and enforcement mechanism, DRI strongly supported the emphasis of Costa Rica and Liechtenstein on the importance of a proactive treaty body, one that does not only respond to state reports but also-and perhaps principally-is able to react effectively and promptly to information and complaints of violations presented by persons with disabilities themselves and those who work with them. Indeed, DRI's experience has shown that situations on the ground rarely change until persons directly affected force that change. Such action nevertheless inevitably requires the support of international oversight bodies empowered to accompany the process of contestation, settlement, reform, follow-up, and supervision. In this regard, DRI underscored three essential elements it believed critical to any international enforcement mechanism: (1) an individual complaints mechanism; (2) precautionary or urgent interim measures; and (3) on-site visits.

With respect to the former, DRI questioned the view of others in the process that collective complaints procedures are preferable to individual communications because they allow structural inequities to be addressed. Indeed, DRI has been highly successful in promoting structural reform in national mental health systems through the use of individual case-based procedures. ${ }^{25}$ Such procedures have the decisive advantage of allowing the concrete specificities and contours of abusive situations to be detailed, allowing for the crafting of more targeted and responsive remedial measures than are generally available through collective complaints processes. Offered within the framework of an "effective remedy," such measures-which include structural guarantees against nonrepetition-can then be the focus of longerterm implementation processes, promoted jointly by international monitoring and on-the-ground civil society mobilization campaigns. 
At the same time, DRI sought to respond to concerns about institutional duplication at the international level by proposing that the Committee might consider endowing the CRPD treaty body with the capacity to refer individual complaints to the corresponding regional human rights system where jurisdictional overlap existed (that is, the Inter-American, European, and African systems) - preferably with its continued participation in an expert advisory capacity. This would simultaneously serve to lessen the workload of the Committee-allowing it to focus on individual complaints in those regions that lack judicial and quasi-judicial human rights bodieswhile also helping to mainstream disability rights protections into human rights treaties that are not disability specific. Because the regional systems are well developed and have generally strong dispute settlement, follow-up, and supervisory procedures, this might have been one innovative step forward for international enforcement.

In emphasizing the need for the new treaty to innovate with respect to international enforcement mechanisms and to avoid the weaknesses of the current treaty-body system, DRI likewise underscored the need for the treaty-body complaints process to be closely linked with processes for integrated follow-up and continual supervision by monitoring bodies, especially given the fact that certain structural reform processes take significant time. Simple recommendations, without a follow-up procedure, would be insufficient and a tremendous lost opportunity for persons with disabilities. At the same time, because international complaints procedures inevitably involve significant delay, DRI believed it essential for the treaty to provide for urgent interim measures to protect persons with disabilities from grave and irreparable harm that can occur while a complaint is being processed. On-site visits, DRI believed, also serve as a critical implementation tool to allow members of the monitoring body to see abuses firsthand, to consult and negotiate directly with decision makers, to hear directly from persons affected, and to put remedial action plans in place in cooperation with responsible governments and in consultation with civil society.

In supporting these positions and others, DRI put forward detailed amendments to the drafting proposals in circulation, seeking to ensure that the treaty body created under the new Convention would indeed innovate beyond the current treaty body structure. Unfortunately, in the end, this did not come to pass. The CRPD treaty body, in its composition and functions, looks almost identical to those of the other major UN human rights treaty bodies. The one innovation in the human rights field was a Conference of 
States Parties, borrowed from the Land Mines Treaty, the effectiveness of which is still to be seen.

\section{Final Reflections}

As pointed out by others in this volume, the final CRPD is not perfect. It contains provisions that could have been better drafted and it omits protections or concepts that some stakeholders would have liked to have seen included. At the same time, significant opportunities for creating new and creative mechanisms at the international level to promote national-level compliance with the CRPD were unfortunately not taken up. Overall, however, the CRPD is a comprehensive and highly useful tool for promoting the rights and dignity of persons with disabilities, and it will have an important impact on the way the rights of persons with disabilities are fought for both domestically and internationally for generations to come.

In contributing to the final treaty outcome, DRI won many of its battles and lost many others. It nonetheless believes that it played an important role in the process, especially in providing a consistent technical perspective on the drafting proposals as they evolved and in maintaining a principled focus on the long-term operability of the treaty text in post-adoption implementation processes. As highlighted earlier, this role served to complement the advocacy role taken by many other DPOs and NGOs in the negotiations and, in the end, strengthened, we believe, the overall civil society presence in the drafting process. At the same time, it is important to recognize that the arguments DRI advanced and the principles it fought for will continue to play a vital and central political role in the much harder implementation work ahead of transforming the substantive norms and process commitments of the CRPD into concrete, meaningful change for affected communities worldwide. 